\title{
Determinants of Pesticide Application in Nepalese Vegetable Farming: An Empirical Analysis using Multivariate Probit Model
}

\author{
- Arun $\mathrm{GC}^{1, *}$ and Kiran Ghimire ${ }^{2}$
}

\begin{abstract}
Currently, the pesticides are the global core concern because it is a boon to farmers against increasing disease-pest and simultaneously, pesticide residue is the major anxiety regarding human health. For that reason, identification and determination of factors affecting the application of pesticides are essential. To identify and evaluate determinants of pesticides application in Nepal, a household survey of 300 households was carried-out and an empirical analysis was done using multivariate probit model. Moreover, powder and liquid forms of pesticides were considered for summer and winter season in vegetable farming, which was assigned as outcome variables. Likewise, socio-economic, demographic, farm-level and perception data were considered as explanatory variables. Use of chemical fertilizers, age and gender of head of household, household size and access to weather information were found the most influencing factors. Moreover, forms of pesticides and growing seasons were found complementary to each other. Therefore, devising the policy options accordingly should balance needs of farmers and health of consumers.
\end{abstract}

\section{Keywords}

Pesticides, Vegetable, Nepal, Determinant, Multivariate Probit

\footnotetext{
${ }^{1}$ College of Agriculture and Life Science, Kyunpook National University, Rep. of Korea 2 Plant Protection Officer, National Plant Quarantine Program, Department of Agriculture, Government of Nepal *Correspondence: arun@knu.ac.kr
} 


\section{Introduction}

Nepal is an agrarian country having one-third contribution to GDP from the agriculture sector and retaining two-third labour force in it (MoF, 2016). Although cereal crops are the major produces in Nepalese agriculture system, occupying 280 thousand hectares, as of 2015/16, the vegetable is one of the significant crop (MoAD, 2017). Moreover, an area of vegetable has increased by $99.86 \%$ from $1991 / 92$ to $2015 / 16$ (MoAD, 2017), and importantly, vegetable farming is one of the major sink of pesticides in Nepal (Atreya et al., 2012).

Pesticide use in Nepal has started since 1995 with an introduction of DDT and BHC (Jasmine et al., July, 2008). Since then, pesticides became one of the priority input in the modern agriculture to raise production by fighting against disease-pest. Another important fact, the losses of crops due to storage and pest were estimated around 30\% (Palikhe, 2002, Upadhyay, 2000, Paneru et al., 1977). If only these losses could be reduced, there would be a considerable increase in availability of food, and thus contributing to the food security (FAO, 2017).

The use of pesticides pound the adverse effect on the human health, land and environment (Gayatri et al., 2016). Likewise, yield loss due to non-target pesticide application resulting in pesticide induced pest resurgence and increasing financial burden to farmers (Wilson and Tisdell, 2001). Thus, the use of pesticides has both positive and negative externalities. Farmers apply chemical pesticides at high dose and frequency, cocktail spray (Aryal, 2014) because of lack of awareness regarding the harmful effects such as cancer, improper fetal development, Parkinson's disease, birth defects, altered growth, acute and chronic toxicity.

Though several studies have carried out regarding uses of pesticide but best on knowledge, none of the studies has been done to determine factor influencing the choice of application of pesticides. Thus, the study aimed to evaluate determinants of pesticides application in vegetable farming in Nepal and calculate its marginal effect in order to quantify it, which enable policymakers in order to devise policy, which balances purpose of plant protection and concern of public health and environment. 


\section{Pesticides consumption in Nepal}

Even though majority of pesticides are consuming in the developed countries, the developing countries are increasing its use. In Nepal, aggregate consumption of pesticides is 396g a.i./ha (PRMS, 2014), which is higher than the previous record 142g a.i./ha (Diwakar et al., 2010). However, it is still lower than the other Asian countries like India, Japan, China, and Korea, which are $0.5,12,14$ and $6.6 \mathrm{~kg} /$ ha respectively, and other countries like the USA and the Europe -7.0 and $2.5 \mathrm{~kg} / \mathrm{ha}$ respectively(2015, Atreya, 2007).

On ecological basis, highest average pesticide used in the Terai region of Nepal i.e. 0.995 a.i. $\mathrm{kg} / \mathrm{ha}$ followed by valley 0.470 a.i. $\mathrm{kg} / \mathrm{ha}$, hill 0.314 a.i. $\mathrm{kg} / \mathrm{ha}$ and lowest in the high hill 0.085 a.i. $\mathrm{kg} / \mathrm{ha}$ (PRMS, 2014). Similarly, heavy pesticide use was found in the Central Development Region (1.015a.i. kg/ha) followed by Eastern Development Region (0.616 a.i. $\mathrm{kg} / \mathrm{ha}$ ), Western Development Region (0.276 a.i. kg/ha), Mid-Western Development Region (0.225 a.i. kg/ha) and least in the Far-Western Development Region (0.146 a.i.kg/ha) (PRMS, 2014).

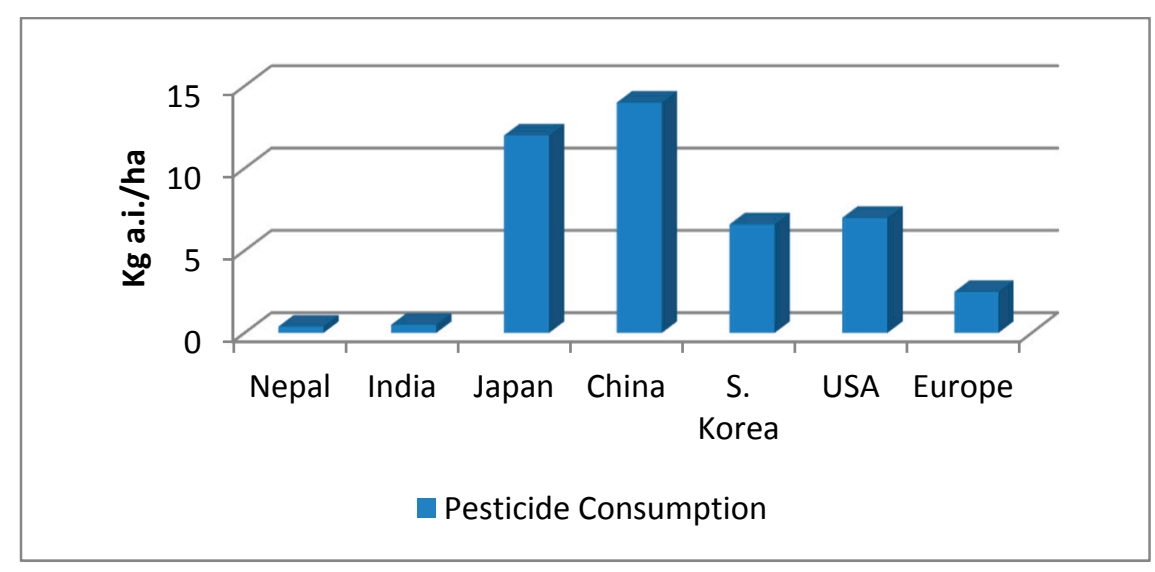

Figure 1: Comparison on National consumption of pesticide

\section{Uses of pesticides in different crop}

The highest share of pesticides was found in vegetables, which accounts for $89 \%$ of the total pesticide use followed by cash crops and found least in cereals as shown in Table 1. 
Table 1: Consumption of pesticide by crop type

\begin{tabular}{|c|c|c|}
\hline S.N. & Crops & Quantity a.i.kg/ha \\
\hline 1 & Cereals & 0.05 \\
\hline 2 & Vegetables & 1.60 \\
\hline 3 & Cash crops & 0.19 \\
\hline 4 & Pulses & 0.05 \\
\hline 5 & Fruits & 0.03 \\
\hline
\end{tabular}

(Source: Survey Report on National Pesticide Consumption Statistics in Nepal, 2014)

\section{Methodology}

\section{Data and Study Location}

A household level survey was carried out in 300 households covering 10 sample districts by random sampling technique. The sample districts were selected to cover all five geographical regions - High Mountain (Mustang), Mountain (Kaski and Rasuwa), Hill (Rolpa, Dadhing, Dadeldhura and Terhathum), Siwalek (Chitwan) and Terai (Parsa and Bardiya).

\section{Empirical Model}

The multivariate probit model is used to study the farmer choices on pesticides application because it can capture latent effects among various choices, which cannot capture by other alternative models (Greene, 2000, Nhemachena et al., 2014, Piya et al., 2013). Moreover, powder and liquid forms of pesticides were considered for summer and winter season in vegetable farming, which were assigned as outcome variables rather than just pesticide. Likewise, socio-economic, demographic, farm-level and perception data were considered as explanatory variables, which are described in Table-2.

The general specification for the MVP is (Greene, 2000)

$$
Z=x_{m}^{\prime} \beta_{m}+\varepsilon_{m}, \quad Z=1 \text { if } Z>0, \text { otherwise } 0, \quad m=1, \ldots \ldots, M,
$$

$E\left[\varepsilon_{m} \mid x_{1}, \ldots, x_{M}\right]=0$, 
$\operatorname{Var}\left[\varepsilon_{m} \mid x_{1}, \ldots, x_{M}\right]=1$

$\operatorname{Cov}\left[\varepsilon_{j} \varepsilon_{m} \mid x_{1}, \ldots, x_{M}\right]=\rho_{j m}$

$\left(\varepsilon_{1}, \ldots \ldots, \varepsilon_{M} \sim N_{M}[0, R]\right.$

Where $\mathrm{x}$ is a covariates matrix having any explanatory variables, $\beta$ is a matrix of unknown regression coefficient and $\varepsilon_{m}$ is a residual error. $\mathrm{R}$ is the variance-covariance matrix. The off-diagonal elements in correlation matrix $\rho_{j m}$ represent the unobserved correlation between the stochastic component of the jth and mth options (Piya, 2013).

The marginal effects of explanatory variables on the propensity to adopt different pesticide options were calculated by following equation (Nhemachena et al., 2014).

$\frac{\partial P_{i}}{\partial x_{i}}=\varphi\left(x^{\prime} \beta\right) \beta_{i}, \quad i=1,2,3, \ldots \ldots, n$

Where $P_{i}$ is the likelihood of event $\mathrm{i}$, which increases adoption of each pesticide forms, $\varphi($.$) is the standard univariate normal density distribution function.$

For this study, STATA 13 was employed and to get consistent estimates number of draws was set to 100, which is 5 by default (Cappellari, 2003 \#164;Piya, 2013 \#26).

\section{Variable Description}

Two forms of pesticides - powder and liquid were considered as outcome variables for two seasons - the winter and the summer. All four outcome variables are binary variables, 1 for using the particular pesticide in the particular season and 0 otherwise. No theory has been developed regarding the selection of explanatory variables for the choice of pesticides uses. However, based on previous empirical analysis regarding pesticides and adaptation following explanatory variables has been selected for the model. The expected relationship between the explanatory and outcome variables are also presented in the table-2. 
Table 2: Variable description

\begin{tabular}{|c|c|c|c|}
\hline Variables & Description & Mean & $\begin{array}{l}\text { Expected } \\
\text { relationship }\end{array}$ \\
\hline WinPwd & $\begin{array}{l}\text { Use of powder formulation of pesticides in winter crops } \\
\text { if YES }=1 \text { otherwise } 0\end{array}$ & .46 & NA \\
\hline SumPwd & $\begin{array}{l}\text { Use of powder formulation of pesticides in summer crops } \\
\text { if YES }=1 \text { otherwise } 0\end{array}$ & .13 & NA \\
\hline WinLiq & $\begin{array}{l}\text { Use of liquid formulation of pesticides in winter crops } \\
\text { if YES }=1 \text { otherwise } 0\end{array}$ & .31 & NA \\
\hline SumLiq & $\begin{array}{l}\text { Use of liquid formulation of pesticides in summer crops } \\
\text { if YES = } 1 \text { otherwise } 0\end{array}$ & .59 & NA \\
\hline WinFert & $\begin{array}{l}\text { Use of chemical fertilizer in winter vegetable } \\
\text { if YES }=1 \text { otherwise } 0\end{array}$ & 0.69 & \pm \\
\hline SumFert & $\begin{array}{l}\text { Use of chemical fertilizer in summer vegetable } \\
\text { if YES }=1 \text { otherwise } 0\end{array}$ & .693 & \pm \\
\hline Temp_C_W & $\begin{array}{l}\text { Perception of temperature change by farmers } \\
\text { if Cooler }=1 \text { otherwise } 0\end{array}$ & 0.88 & \pm \\
\hline SumVeg & $\begin{array}{l}\text { Growing summer vegetable } \\
\text { if YES }=1 \text { otherwise } 0\end{array}$ & 0.24 & + \\
\hline WinVeg & $\begin{array}{l}\text { Growing winter vegetable } \\
\text { if YES }=1 \text { otherwise } 0\end{array}$ & 0.47 & + \\
\hline GenderHoH & $\begin{array}{l}\text { Gender of Head of Household } \\
\text { if Female }=1 \text { otherwise } 0\end{array}$ & 0.07 & \pm \\
\hline HHSize & Number of family member in a household & 5.88 & \pm \\
\hline Weatherinfo & $\begin{array}{l}\text { Having access to weather information } \\
\text { if YES }=1 \text { otherwise } 0\end{array}$ & 0.60 & + \\
\hline AgeHoH & Age of head of household in year & 49.99 & - \\
\hline BorrowYN & $\begin{array}{l}\text { Household having credit access } \\
\text { if YES= } 1 \text { otherwise } 0\end{array}$ & 0.42 & + \\
\hline Extension1 & $\begin{array}{l}\text { Household having access to extension service } \\
\text { if YES }=1 \text { otherwise } 0\end{array}$ & 0.79 & + \\
\hline Pest_MoreLess & $\begin{array}{l}\text { Perception of famers' on change in disease pest incidence } \\
\text { if Increasing = } 1 \text { otherwise } 0\end{array}$ & 0.07 & + \\
\hline FarmArea & Household farming area in hacters & 0.93 & \pm \\
\hline EducHoH & Education level of head of household in school years & 7.33 & + \\
\hline Drght_MoreLess & $\begin{array}{l}\text { Perception of farmers on change in drought frequency } \\
\text { if More }=1 \text { otherwise } 0\end{array}$ & 0.19 & + \\
\hline PctOnfarmlncome & $\begin{array}{l}\text { Percentage of income coming from farming to total household } \\
\text { income }\end{array}$ & 69.99 & \pm \\
\hline
\end{tabular}

\section{Result and Discussion}

The results from the MVP model shows that farmers growing the vegetable crops are highly likely to use pesticides. Interestingly, liquid-form of the pesticides is more likely to use in the winter vegetable, whereas, the powder form of pesticides are more likely to use in the summer vegetables. More importantly, farmers using chemical fertilizer are highly likely to use 
liquid pesticides in winter vegetables and powder form of the pesticides in the summer vegetables. However, farmers are less likely to use the powder form of the pesticides in winter vegetables if they are using chemical fertilizer, whereas, similar is the likelihood in the summer vegetables if they are using chemical fertilizers.

In case of perception of temperature change, if farmers perceived the temperature is going cooler, they are less likely to use pesticides, implying increasing temperature is also promoting the use of pesticides. Similarly, increasing frequency of drought in summer vegetables also highly likely to increases the use of powder form of the pesticides. Thus, it is also indicating that climate change is causing boosting of disease-pest, which increases the use of the pesticides. The results show that winter pests are increasing than summer pest because increasing pest and use of liquid pesticides are highly significant in the winter vegetables.

Increasing number of member of the household is decreasing the likelihood of powder pesticides in summer and rest relations are not found significant. Similarly, young farmers are more likely to use pesticides as compared to old farmers. Likewise, female head of households are also less likely to adopt pesticides as compared to male. Importantly, role of the education was not found significant in any case. In case of farm area, only powder pesticides in summer vegetable were found significant and were positively associated, implying increasing area increases the likelihood of pesticide adoption.

Percentage of income coming from farming to total household income was not found significant. It implies that farmers are using pesticides irrespective of the share of farm income in their total household income. However, if the households have credit access, they are more likely to use the powder form of pesticides in the summer. Similarly, households having weather information are more likely to use the powder form of pesticides in the summer, whereas other seasons and forms were not found significant. Likewise, extension service is effective in winter to use liquid pesticides. If the households have access to extension services, they are more likely to adopt liquid pesticides in the winter. 
Table 3: The MVP model result

\begin{tabular}{|c|c|c|c|c|}
\hline VARIABLES & WinPwd & SumPwd & WinLiq & SumLiq \\
\hline \multirow{2}{*}{ WinVeg } & 0.38 & -0.10 & $0.59 * *$ & -0.17 \\
\hline & $(0.24)$ & $(0.28)$ & $(0.27)$ & $(0.22)$ \\
\hline \multirow{2}{*}{ WinFert } & $-0.82 * * *$ & -0.02 & $1.44 * * *$ & 0.005 \\
\hline & $(0.30)$ & $(0.39)$ & $(0.34)$ & $(0.29)$ \\
\hline \multirow{2}{*}{ SumVeg } & $-0.51^{*}$ & $0.74^{* *}$ & -0.27 & 0.22 \\
\hline & $(0.27)$ & $(0.32)$ & $(0.33)$ & $(0.27)$ \\
\hline \multirow{2}{*}{ SumFert } & 0.12 & $0.98 * *$ & $-0.70 * *$ & 0.08 \\
\hline & $(0.32)$ & $(0.50)$ & $(0.35)$ & $(0.31)$ \\
\hline \multirow{2}{*}{ Temp_C_W } & $-0.62^{* *}$ & $-1.04 * * *$ & $-0.59 *$ & -0.27 \\
\hline & $(0.31)$ & $(0.40)$ & $(0.35)$ & $(0.34)$ \\
\hline \multirow{2}{*}{ Drght_MoreLess } & -0.06 & $0.93^{* * *}$ & -0.17 & 0.0004 \\
\hline & $(0.28)$ & $(0.31)$ & $(0.33)$ & $(0.29)$ \\
\hline \multirow{2}{*}{ Pest_MoreLess } & 0.37 & -0.36 & $1.69 * * *$ & -0.05 \\
\hline & $(0.38)$ & $(0.47)$ & $(0.45)$ & $(0.42)$ \\
\hline \multirow{2}{*}{ HHSize } & 0.06 & $-0.17^{* *}$ & 0.035 & 0.07 \\
\hline & $(0.04)$ & $(0.07)$ & $(0.05)$ & $(0.04)$ \\
\hline \multirow{2}{*}{ AgeHoH } & -0.01 & $-0.03 * *$ & 0.0006 & -0.005 \\
\hline & $(0.01)$ & $(0.01)$ & $(0.01)$ & $(0.01)$ \\
\hline \multirow{2}{*}{ GenderHoH } & 0.73 & $-5.56 * * *$ & -0.66 & 0.40 \\
\hline & $(0.47)$ & $(0.63)$ & $(0.47)$ & $(0.47)$ \\
\hline \multirow{2}{*}{ EducHoH } & 0.01 & 0.0001 & 0.01 & 0.023 \\
\hline & $(0.02)$ & $(0.03)$ & $(0.03)$ & $(0.03)$ \\
\hline \multirow{2}{*}{ FarmArea } & -0.12 & $0.40^{*}$ & -0.10 & -0.004 \\
\hline & $(0.14)$ & $(0.21)$ & $(0.16)$ & $(0.14)$ \\
\hline \multirow{2}{*}{ PctOnfarmlncome } & -0.0004 & -0.0002 & -0.002 & -0.001 \\
\hline & $(0.003)$ & $(0.005)$ & $(0.004)$ & $(0.003)$ \\
\hline \multirow{2}{*}{ BorrowedYN } & 0.25 & $0.61 * *$ & 0.33 & -0.11 \\
\hline & $(0.23)$ & $(0.30)$ & $(0.24)$ & $(0.23)$ \\
\hline \multirow{2}{*}{ WeatherInfo } & -0.27 & $0.59 *$ & 0.28 & 0.004 \\
\hline & $(0.22)$ & $(0.32)$ & $(0.25)$ & $(0.22)$ \\
\hline \multirow{2}{*}{ Extension1 } & 0.29 & -0.14 & $0.77^{* *}$ & -0.007 \\
\hline & $(0.28)$ & $(0.35)$ & $(0.34)$ & $(0.26)$ \\
\hline \multirow{2}{*}{ Constant } & 0.94 & 0.06 & $-1.80 * *$ & 0.18 \\
\hline & $(0.79)$ & $(1.07)$ & $(0.83)$ & $(0.83)$ \\
\hline
\end{tabular}

\section{Correlation Coefficients of outcome variables}

One of the most important uses of the MVP is the capturing interaction among the outcome variables. The MVP results on correlation coefficients show that the powder form of pesticides in winter vegetables and summer vegetables, the powder and liquid form of pesticides in the summer vegetables, the liquid form of pesticides in the winter and the summer vegetables 
are highly inter-related. More importantly, they are positively associated, indicating, they can be promoted or discouraged simultaneously.

Table 4: Correlation Coefficients of outcome variables

\begin{tabular}{|c|ccc|}
\hline & Rho1 & Rho2 & Rho3 \\
\hline Rho2 & $0.47^{* * *}$ & & \\
& $(0.18)$ & -0.17 & \\
Rho3 & -0.20 & $(0.19)$ & $0.51^{* * *}$ \\
& $(0.15)$ & $0.44^{* *}$ & $(0.16)$ \\
\hline
\end{tabular}

\section{Marginal effects}

Without the marginal effects, the MVP can just calculate a likelihood of occurrence of the event. Thus, the marginal effect enables to quantify the impact of each explanatory variable in the model. The detail result of the marginal effect is presented in Table 5.

The results show that half of the variables are positively and half of the variables are negatively affecting the adoption decision for use of pesticides in general. The chemical fertilizer in the winter season was found most influencing explanatory variable with a negative association. It means if farmers are using an appropriate amount of chemical fertilizer can reduce the use of pesticide significantly $(-0.82)$ and similar is the case for temperature $(-0.62)$. However, controlling temperature is not an easy task. Nevertheless, it suggests that production of vegetables in controlled environment - like the green house and the smart farming could reduce the use of the pesticide remarkably. Another interesting fact, the winter vegetable is consuming more pesticides than the summer vegetables. Further research is suggested to understand the detail about the finding. Despite the previous result of the negative association between gender and adoption of the pesticides, the marginal effect produced positive association, indicating being female as the head of household increases the likelihood of adoption of the pesticide by 0.73. Likewise, each year increase in the head of household decrease the likelihood of adoption of the pesticides by 0.01 . 
Table 5: Marginal Effect

\begin{tabular}{|c|c|c|c|c|c|c|}
\hline variable & $d y / d x$ & $z$ & $P>Z$ & [ $95 \%$ & C.I. ] & $\mathrm{x}$ \\
\hline WinFert* & $\begin{array}{l}-0.82 \\
(0.30)\end{array}$ & -2.75 & 0.006 & -1.40651 & -0.236 & 0.691358 \\
\hline Temp_C_W* & $\begin{array}{l}-0.62 \\
(0.31)\end{array}$ & -1.99 & 0.047 & -1.24035 & -0.00802 & 0.876543 \\
\hline SumVeg* & $\begin{array}{l}-0.51 \\
(0.27)\end{array}$ & -1.93 & 0.054 & -1.03357 & 0.008759 & 0.240741 \\
\hline WinVeg* & $\begin{array}{c}0.38 \\
(0.24)\end{array}$ & 1.6 & 0.11 & -0.0867 & 0.850763 & 0.469136 \\
\hline GenderHoH* & $\begin{array}{c}0.73 \\
(0.47)\end{array}$ & 1.55 & 0.121 & -0.19162 & 1.64749 & 0.061728 \\
\hline HHSize & $\begin{array}{c}0.06 \\
(0.04)\end{array}$ & 1.46 & 0.145 & -0.02187 & 0.148117 & 5.88272 \\
\hline Weatherinfo* & $\begin{array}{l}-0.27 \\
(0.22)\end{array}$ & -1.22 & 0.224 & -0.71054 & 0.166487 & 0.604938 \\
\hline AgeHoH & $\begin{array}{l}-0.01 \\
(0.01)\end{array}$ & -1.2 & 0.23 & -0.032 & 0.007696 & 49.9877 \\
\hline BorrowYN* & $\begin{array}{c}0.25 \\
(0.23)\end{array}$ & 1.07 & 0.286 & -0.20696 & 0.701696 & 0.419753 \\
\hline Extension1* & $\begin{array}{c}0.29 \\
(0.28)\end{array}$ & 1.05 & 0.295 & -0.25152 & 0.829622 & 0.790123 \\
\hline Pest_M s* & $\begin{array}{c}0.37 \\
(0.39)\end{array}$ & 0.97 & 0.331 & -0.3797 & 1.12731 & 0.074074 \\
\hline FarmArea & $\begin{array}{l}-0.12 \\
(0.14)\end{array}$ & -0.87 & 0.386 & -0.40264 & 0.155622 & 0.933765 \\
\hline EducHoH & $\begin{array}{c}0.01 \\
(0.02)\end{array}$ & 0.44 & 0.657 & -0.02948 & 0.04672 & 7.33333 \\
\hline SumFert* & $\begin{array}{c}0.12 \\
(0.32)\end{array}$ & 0.37 & 0.708 & -0.50222 & 0.739162 & 0.771605 \\
\hline Drght_ s* $^{*}$ & $\begin{array}{l}-0.06 \\
(0.28)\end{array}$ & -0.22 & 0.825 & -0.61573 & 0.490928 & 0.185185 \\
\hline PctOnfarmIncome & $\begin{array}{l}-0.0004 \\
0.004\end{array}$ & -0.11 & 0.912 & -0.00716 & 0.006393 & 69.9877 \\
\hline
\end{tabular}

$\left({ }^{*}\right) \mathrm{dy} / \mathrm{dx}$ is for discrete change of dummy variable from 0 to 1

\section{Conclusion}

The determinants of pesticides application in Nepalese vegetable farming was identified and evaluated, and the marginal effects of each explanatory variable were calculated. Disintegrating vegetable farming into the winter and the summer provides the deeper 
understanding of dynamics of use of the pesticides and further enriched by disintegrating pesticides into its two forms.

The winter vegetables are more likely to consume liquid forms of pesticides and the summer vegetables are more likely to consume powder form of pesticides. Interestingly, the use of chemical fertilizer is likely to produce different forms of the pesticides in the different season and simultaneously discouraging another form of the pesticides. The result supports to establish the relationship between the climate change and disease-pest and suggests the promotion of technological advancement in vegetable farming, which could be the protected farming like the greenhouse or the smart farming. Likewise, household access to information is also influencing the farmers' decision on adoption of the pesticides thus the extension services can be used effectively to achieve the policy objective of the government. Similarly, very expectedly, household characteristics are influencing variables on the adoption. Finally, the correlation coefficients of the outcome variables are significant and positive, they can be promoted or discouraged simultaneously, which an advantage to the government. 


\section{Reference}

2015. Economic Survey 2015-16. Kathmandu: Ministry of Finance, Government of Nepal.

ARYAL, S. 2014. Review on the pesticide residue works in Nepal.

ATREYA, K. 2007. Pesticide Use in Nepal: Understanding Health Costs from Short-term Expouser. Kathmandu: South Asian Network for Development and Environmental Economics (SANDEE).

ATREYA, K., JOHNSEN, F. H. \& SITAULA, B. K. 2012. Health and environmental costs of pesticide use in vegetable farming in Nepal. Environment, Development and Sustainability, 14, 477-493.

DIWAKAR, J., PRASAI, T., PANT, S. R. \& JAYANA, B. L. 2010. Study on Major Pesticides and Fertilizers used in Nepal. Scientific World, 6.

FAO. 2017. Food Loss and Food Waste [Online]. Rome: Food and Agriculture Organization of the United Nations. Available: http://www.fao.org/food-loss-and-food-waste/en/ [Accessed 2017].

GAYATRI, K., AMARJEET, S. \& GOVINDA, D. 2016. Pesticide Poisoning Among Commercial Vegetable Farmers of Chitwan, Nepal. Primary Prevention Insights U6 - ctx_ver=Z39.882004\&ctx_enc=info\%3Aofi\%2Fenc\%3AUTF-

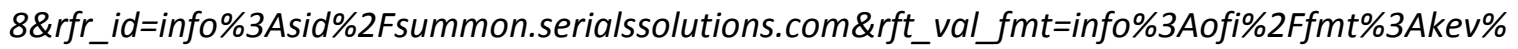
3Amtx\%3Ajournal\&rft.genre $=$ article\&rft.atitle $=$ Pesticide + Poisoning + Among + Commercial+Vegeta ble+Farmers+of+Chitwan\%2C+Nepal\&rft.jtitle=Primary+Prevention+Insights\&rft.au=Khanal+Gay atri\&rft.au=Singh+Amarjeet\&rft.au=Dhungana+Govinda\&rft.date $=2016-01-$

$01 \&$ rft.pub=Sage+Publications+Ltd\&rft.eissn $=1179$ -

1748\&rft.volume=6\&rft.spage=19\&rft.externalDoclD=4230299641\&paramdict=en-US U7 Journal Article, 6, 19.

GREENE, W. H. 2000. Econometric Analysis, New Jersy, Prentice Hall International, Inc.

JASMINE, D., PRASAI, T., PANT, S. R. \& JAYANA, B. L. July, 2008. Study on Major Pesticides and Fertilizers Used in Nepal. Scientific World, 76-80.

MOAD 2017. Statistical Information on Nepalese Agriculture 2072/73 (2015/16). Kathmandu, Nepal: Ministry of Agricultural Development.

MOF 2016. Economic Survey Fiscal Year 2016/17. Kathmandu Ministry of Finance, Government of Nepal.

NHEMACHENA, C., HASSAN, R. \& CHAKWIZIRA, J. 2014. Analysis of determinants of farm-level adaptation measures to climate change in Southern Africa. Journal of Development and Agricultural Econonomics, 232-241.

PALIKHE, B. R. 2002. Challenges and options of pesticide use: in the context of Nepal. Landschaftsokologie Umweltforsch, 130-141.

PANERU, R. B., DAWADI, V. R. \& KHANAL, R. 1977. Effect of houehold lime on maize weevil in stored maize. Dhankuta, Nepal: Pakhribas Agricultural Center.

PIYA, L., MAHARJAN, K. L. \& JOSHI, N. P. 2013. Determinants of adaptation practices to climate change by Chepang households in the rural Mid-Hills of Nepal. Regional Environmental Change, 437-447.

PRMS 2014. Study on National Pesticide Consumption Statistics. Kathmandu.

UPADHYAY, U. P. 2000. A proposed report on reducing post harvest loss.

WILSON, C. \& TISDELL, C. 2001. Why farmers continue to use pesticides despite environmental, health and sustainability costs. Ecological Economics, 39, 449-462. 